\title{
An Improved Tank in Series Model for the Direct Methanol Fuel Cell
}

\author{
Valery A. Danilov, ${ }^{1,2}$ Joeri Denayer, ${ }^{1}$ and Il Moon $^{3}$ \\ ${ }^{1}$ Department of Chemical Engineering, Vrije Universiteit Brussel, Pleinlaan 2, Elsene, 1050 Brussel, Belgium \\ ${ }^{2}$ Department of Processes and Unit Operations of Chemical Technology, Kazan State Technological University, Kazan, \\ Tatarstan 420015, Russia \\ ${ }^{3}$ Department of Chemical Engineering, Yonsei University, Shinchon-dong 134, Seoul 120-749, Republic of Korea
}

Correspondence should be addressed to Joeri Denayer, joeri.denayer@vub.ac.be

Received 9 March 2011; Accepted 27 April 2011

Academic Editor: Changwei Xu

Copyright (C 2011 Valery A. Danilov et al. This is an open access article distributed under the Creative Commons Attribution License, which permits unrestricted use, distribution, and reproduction in any medium, provided the original work is properly cited.

\begin{abstract}
This study presents an improved TSR model for Direct Methanol Fuel Cell (DMFC) with mass and energy balance equations taking into account gas evolution in the anode channels. The TSR model includes a modified charge balance equation suitable for potentiostatic fuel cell operation mode. Polarization curves calculated with the improved TSR model agree with experimental data from the literature. The developed TSR model is able to approximate two-dimensional concentration, temperature, and current density profiles in DMFC with parallel flow field.
\end{abstract}

\section{Introduction}

The direct methanol fuel cell is a potential energy source to replace batteries for portable electronics. The main attractive features of DMFC include high energy density and nearly zero recharge time. Numerous $1 \mathrm{D}$ and 3D models are available for DMFC in the literature. Kulikovsky presented a 1D isothermal model for DMFC [1]. Murgia et al. developed 1D multicomponent steady-state isothermal model for liquid-feed DMFC [2]. Hyun et al. predicted the DMFC performance for different anode flow field designs using computational simulations [3]. Danilov et al. developed the two-phase model with a submodel for interphase transfer. They used CFD-based DMFC model to visualize and analyze the gas evolution and flow patterns in the anode channels [4-6]. In contrast to the CFD technique with highly complex process description, lumped parameter models with a reactor network are computationally fast, approximating flow patterns and concentration profiles in fuel cells. Sundmacher et al. [7-10] developed CSTR and TSR models for DMFC operating in galvanostatic mode. They used a tank in series reactor model to investigate the influence of the anode flow fields on the steady-state and dynamic behavior of DMFC with parallel, spot, and rhomboidal designs. Our previous studies focused on TSR model development for solid oxide fuel cells $[11,12]$. The objective of this research is to modify this TSR model for DMFC operating in potentiostatic mode.

\section{Model Formulation}

2.1. TSR Model for Cocurrent Flow DMFC. Fuel and oxidant flow inside the fuel cell with parallel channels can be approximated as a reactor network complying with a tank in series model. Figure 1 illustrates the application of a tank in series reactor (TSR) model for cocurrent flow mode in a planar fuel cell with parallel flow field design.

The developed TSR model for DMFC is based on the following assumptions.

(i) Each anode and cathode compartment is treated as a TSR.

(ii) Electrochemical reactions occur at the electrode/ membrane interfaces.

(iii) Fuel cell operates under the potentiostatic operating mode and constant pressure. 


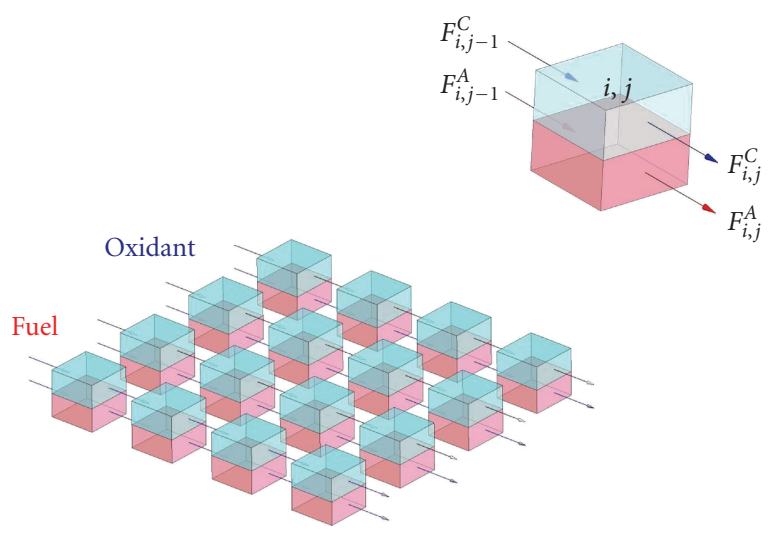

FIGURE 1: TSR model for cocurrent flow DMFC.

(iv) Negligible contact resistances between components.

(v) Negligible evaporation and condensation in cathode channels.

(vi) Uniform distribution of fuel and oxidant in channels.

Balance equations are composed for channel compartment and catalyst layer in each tank. For fuel cells with cocurrent flow mode, the mass balance equations for the anode and cathode channels are written as follows:

$$
\begin{array}{r}
V_{i, j}^{A} \frac{d C_{A, i, j}^{(k)}}{d t}=C_{A, i, j-1}^{(k)} F_{i, j-1}^{A}-C_{i, j}^{(k)} F_{L, i, j}^{A}-N_{A, i, j}^{(k)}, \\
k=\mathrm{MeOH}, \mathrm{CO}_{2}, \mathrm{H}_{2} \mathrm{O}, \\
V_{i, j}^{C} \frac{d C_{C, i, j}^{(k)}}{d t}=C_{C, i, j-1}^{(k)} F_{i, j-1}^{C}-C_{C, i, j}^{(k)} F_{i, j}^{C}-N_{C, i, j}^{(k)}, \\
k=\mathrm{O}_{2}, \mathrm{H}_{2} \mathrm{O}, \mathrm{N}_{2} .
\end{array}
$$

Gas evolution in the anode channels is defined by the following balance equation for the gas phase:

$$
V_{i, j}^{A} \frac{d \varphi_{G, i, j}^{A}}{d t}=\varphi_{G, i, j-1}^{A} F_{i, j-1}^{A}-\varphi_{G, i, j}^{A} F_{i, j}^{A}-\frac{r_{\text {desorp }, i, j}^{A}}{\rho_{\text {mol }, L}^{A}},
$$

In cocurrent flow mode, the fuel and oxidant outgoing streams from tank $i, j-1$, are the inlet streams into tank $i, j$. Therefore, the inlet flow rate for each tank depends on the outgoing flow rate of the previous tank:

$$
\begin{aligned}
& F_{i, j}^{A}=F_{i, j-1}^{A}-\frac{\left(N_{A, i, j}^{\mathrm{MeOH}}+N_{A, i, j}^{\mathrm{CO}_{2}}+N_{A, i, j}^{\mathrm{H}_{2} \mathrm{O}}\right)}{\left(C_{A, i, j}^{\mathrm{MeOH}}+C_{A, i, j}^{\mathrm{CO}_{2}}+C_{A, i, j}^{\mathrm{H}_{2} \mathrm{O}}\right)}, \\
& F_{i, j}^{C}=F_{i, j-1}^{C}-\frac{\left(N_{C, i, j}^{\mathrm{O}_{2}}+N_{C, i, j}^{\mathrm{H}_{2} \mathrm{O}}\right)}{\left(C_{C, i, j}^{\mathrm{O}_{2}}+C_{C, i, j}^{\mathrm{H}_{2} \mathrm{O}}+C_{C, i, j}^{\mathrm{N}_{2}}\right)},
\end{aligned}
$$

Here $V_{i, j}^{A}, V_{i, j}^{C}$ represent the volume of anode and cathode channels in tank $(i, j), V_{i, j}^{A}=V^{A} /\left(n_{i} n_{j}\right), V_{i, j}^{C}=V^{C} /\left(n_{i} n_{j}\right)$; $S_{i, j}$ electrode area in $\operatorname{tank}(i, j), S_{i, j}=S_{\text {cell }} /\left(n_{i} n_{j}\right)$.
Component balance equations for the anode and cathode catalyst layers reflect changes due to consumption and production of species via reaction and mass transfer:

$$
\begin{aligned}
& V_{\mathrm{cat}, i, j}^{A} \frac{d C_{A, \mathrm{cat}, i, j}^{(k)}}{d t}=N_{A, i, j}^{(k)}-r_{A, i, j}^{(k)}, \quad k=\mathrm{MeOH}, \mathrm{CO}_{2}, \mathrm{H}_{2} \mathrm{O} \\
& V_{\mathrm{cat}, i, j}^{C} \frac{d C_{C, \mathrm{cat}, i, j}^{(k)}}{d t}=N_{C, i, j}^{(k)}-r_{C, i, j}^{(k)}, \quad k=\mathrm{O}_{2}, \mathrm{H}_{2} \mathrm{O}
\end{aligned}
$$

Here $V_{\text {cat }, i, j}^{C}, V_{\text {cat }, i, j}^{A}$ correspond to the volume of anode and cathode catalyst layer in $\operatorname{tank}(i, j), V_{\mathrm{cat}, i, j}^{C}=V_{\mathrm{cat}}^{C} /\left(n_{i} n_{j}\right)$, $V_{\text {cat }, i, j}^{A}=V_{\text {cat }}^{A} /\left(n_{i} n_{j}\right)$.

The energy balances for the channels and the MEA structure in tank $i, j$ are written as follows:

$$
\begin{aligned}
& V_{i, j}^{A} \rho_{\mathrm{mol}, L}^{A} C_{p, L}^{A} \frac{d T_{L, i, j}^{A}}{d t} \\
& =\left(\rho_{\mathrm{mol}, L}^{A} F_{i, j-1}^{A} \Delta h_{L, i, j-1}^{A}-\rho_{\mathrm{mol}, L}^{A} F_{i, j}^{A} \Delta h_{L, i, j}^{A}\right) \\
& \quad+q_{L, i, j}^{A}+q_{\mathrm{coll}, i, j}^{A}, \\
& V_{G, i, j}^{C} \rho_{\mathrm{mol}, G}^{C} C_{p, G}^{C} \frac{d T_{G, i, j}^{C}}{d t} \\
& =\left(\rho_{\mathrm{mol}, G}^{C} F_{i, j-1}^{C} \Delta h_{G, i, j-1}^{C}-\rho_{\mathrm{mol}, \mathrm{G}}^{C} F_{i, j}^{C} \Delta h_{G, i, j}^{C}\right) \\
& \quad+q_{G, i, j}^{C}+q_{\mathrm{coll}, i, j}^{C}, \\
& V_{i, j}^{S} \rho C_{p}^{S} \frac{d T_{i, j}^{S}}{d t}=q_{i, j}^{S}-q_{L, i, j}^{A}-q_{G, i, j}^{C} .
\end{aligned}
$$

Here $q_{G, i, j}^{C}, q_{L, i, j}^{A}$ represent the convective heat transferred from the MEA to the channel in tank $i, j ; q_{\text {coll }, i, j}^{C}, q_{\text {coll }, i, j}^{A}$ represent heat source due to heat transfer from channel to the collector; $q_{i, j}^{S}$ represents the heat generation in MEA in tank $i, j$.

The charge balance equations for anode and cathode electrode/membrane interfaces are given by

$$
\begin{aligned}
& C_{d l}^{A} \frac{d \eta_{i, j}^{A}}{d t}=I_{i, j}^{\text {cell }}-I_{i, j}^{A}, \\
& C_{d l}^{C} \frac{d \eta_{i, j}^{C}}{d t}=-I_{i, j}^{\text {cell }}-\left(I_{i, j}^{C}+I_{i, j}^{\text {par }}\right) .
\end{aligned}
$$

For $j=1$ tanks, representing the inlet sections of the anode and cathode channels, we obtain the following balance equations:

$$
\begin{array}{r}
V_{i, 1}^{A} \frac{d C_{A, i, 1}^{(k)}}{d t}=C_{A, i, \mathrm{in}}^{(k)} F_{i, \mathrm{in}}^{A}-C_{A, i, 1}^{(k)} F_{i, 1}^{A}-N_{A, i, 1}^{(k)}, \\
k=\mathrm{MeOH}, \mathrm{CO}_{2}, \mathrm{H}_{2} \mathrm{O},
\end{array}
$$




$$
\begin{gathered}
V_{i, 1}^{C} \frac{d C_{C, i, 1}^{(k)}}{d t}=C_{C, i, \text { in }}^{(k)} F_{i, \text { in }}^{C}-C_{C, i, 1}^{(k)} F_{i, 1}^{C}-N_{C, i, 1}^{(k)}, \\
k=\mathrm{O}_{2}, \mathrm{H}_{2} \mathrm{O}, \mathrm{N}_{2}, \\
V_{i, 1}^{A} \frac{d \varphi_{G, i, 1}^{A}}{d t}=\varphi_{G, i, \text { in }}^{A} F_{i, \text { in }}^{A}-\varphi_{G, i, 1}^{A} F_{i, 1}^{A}-\frac{r_{\text {desorp }, i, 1}^{A}}{\rho_{\text {mol }, L}^{A}}, \\
F_{i, 1}^{A}=F_{i, \text { in }}^{A}-\frac{\left(N_{A, i, 1}^{\mathrm{MeOH}}+N_{A, i, 1}^{\mathrm{CO}_{2}}+N_{A, i, 1}^{\mathrm{H}_{2} \mathrm{O}}\right)}{\left(C_{A, i, 1}^{\mathrm{MeO}}+C_{A, i, 1}^{\mathrm{CO}_{2}}+C_{A, i, 1}^{\mathrm{H}_{2} \mathrm{O}}\right)}, \\
F_{i, 1}^{C}=F_{i, \text { in }}^{C}-\frac{\left(N_{C, i, 1}^{\mathrm{O}_{2}}+N_{C, i, 1}^{\mathrm{H}_{2} \mathrm{O}}\right)}{\left(C_{C, i, 1}^{\mathrm{O}_{2}}+C_{C, i, 1}^{\mathrm{H}_{2} \mathrm{O}}+C_{C, i, 1}^{\mathrm{N}_{2}}\right)},
\end{gathered}
$$

where $F_{i, \text { in }}^{A}=F_{\text {in }}^{A} / n_{i}$ is the inlet anode volumetric flow rate for $(i, j)$ tank with $j=1 ; F_{i, \text { in }}^{C}=F_{\text {in }}^{C} / n_{i}$ is the inlet cathode volumetric flow rate for $(i, j)$ tank with $j=1$.

For $j=n_{j}$ tanks, corresponding to the outlet section of fuel and oxidant gas channels, we define mean outlet variables as follows:

$$
\begin{gathered}
F_{\text {out }}^{A}=\sum_{i=1}^{n_{i}} F_{i, n_{j}}^{A}, \quad C_{\text {out }}^{\mathrm{MeOH}}=\frac{\sum_{i=1}^{n_{i}} C_{A, i, n_{j}}^{\mathrm{MeOH}} F_{i, n_{j}}^{A}}{F_{\text {out }}^{A}}, \\
T_{L, \text { out }}^{A}=\frac{\sum_{i=1}^{n_{i}} T_{L, i, n_{j}}^{A} F_{i, n_{j}}^{A}}{F_{\text {out }}^{A}}, \quad F_{\text {out }}^{C}=\sum_{i=1}^{n_{i}} F_{i, n_{j}}^{C}, \\
C_{\text {out }}^{\mathrm{O}_{2}}=\frac{\sum_{i=1}^{n_{i}} C_{C, i, n_{j}}^{\mathrm{O}_{2}} F_{i, n_{j}}^{C}}{F_{\text {out }}^{C}}, \quad T_{G, \text { out }}^{C}=\frac{\sum_{i=1}^{n_{i}} T_{G, i, n_{j}}^{C} F_{i, n_{j}}^{C}}{F_{\text {out }}^{C}} .
\end{gathered}
$$

The developed mathematical model includes the following phenomena:

(i) electrochemical oxidation of methanol at the anode electrode/membrane interface,

(ii) electrochemical reduction of oxygen at the cathode electrode/membrane interface,

(iii) charge balances at anode and cathode electrode/ membrane interfaces,

(iv) energy balances in gas channels and in MEA.

\subsection{The Electrochemistry Submodel}

2.2.1. Electrode Current. The rate of electrochemical reactions is defined by Butler-Volmer equation. The anode reaction rate is

$$
\begin{aligned}
\mathrm{I}_{i, j}^{A}=I_{0}^{A}\left(\frac{C_{\mathrm{cat}, i, j}^{\mathrm{MeH}}}{C_{\mathrm{ref}}^{\mathrm{MeOH}}}\right)^{0.5} \\
\times\left[\exp \left(\frac{\alpha_{A}^{A} F}{R T_{i, j}}\left(\eta_{i, j}^{A}-\eta_{\mathrm{eq}}^{A}\right)\right)\right. \\
\left.\quad-\exp \left(-\frac{\alpha_{C}^{A} F}{R T_{i, j}}\left(\eta_{i, j}^{A}-\eta_{\mathrm{eq}}^{A}\right)\right)\right],
\end{aligned}
$$

where $I_{0}^{A}$ is the anode exchange current density.
The cathode reaction rate is

$$
\begin{aligned}
I_{i, j}^{C}=I_{0}^{C} \frac{C_{\mathrm{cat}, i, j}^{\mathrm{O}_{2}}}{C_{\mathrm{ref}}^{\mathrm{O}_{2}}} & {\left[\exp \left(\frac{\alpha_{A}^{C} F}{R T_{i, j}}\left(\eta_{i, j}^{C}-\eta_{\mathrm{eq}}^{C}\right)\right)\right.} \\
& \left.-\exp \left(-\frac{\alpha_{C}^{C} F}{R T_{i, j}}\left(\eta_{i, j}^{C}-\eta_{\mathrm{eq}}^{C}\right)\right)\right],
\end{aligned}
$$

where $I_{0}^{C}$ is the cathode exchange current density.

Parasitic current is calculated as methanol molar flux from anode catalyst layer to cathode catalyst layer with a linear profile in the membrane:

$$
I_{i, j}^{\mathrm{par}}=n_{e}^{A} F \frac{D_{m}^{\mathrm{MeOH}}}{\delta_{m}}\left(C_{A, \mathrm{cat}, i, j}^{\mathrm{MeOH}}-0\right) .
$$

Source terms in the component balance equations reflect changes due to the consumption or production of species via reaction or mass transfer. For component balance equations in anode catalyst layer (4), the rate of electrochemical reaction is given by

$$
\begin{aligned}
r_{A, i, j}^{\mathrm{MeOH}} & =S_{i, j} \frac{\nu^{\mathrm{MeOH}}}{n_{e}^{A} F} I_{i, j}^{A}, \\
r_{A, i, j}^{\mathrm{CO}_{2}} & =S_{i, j} \frac{\nu^{\mathrm{CO}_{2}}}{n_{e}^{A} F} I_{i, j}^{A}, \\
r_{A, i, j}^{\mathrm{H}_{2} \mathrm{O}} & =S_{i, j} \frac{\nu^{\mathrm{H}_{2} \mathrm{O}}}{n_{e}^{A} F}\left(I_{i, j}^{A}\right)-S_{i, j} n_{d, i, j} \frac{I_{i, j}^{A}}{F},
\end{aligned}
$$

where $n_{d, i, j}$ represents the electro-osmotic drag coefficient.

For balance equations in cathode catalyst layer (5), the rate of electrochemical reaction is

$$
r_{C, i, j}^{\mathrm{O}_{2}}=S_{i, j} \frac{\nu^{\mathrm{O}_{2}}}{n_{e}^{C} F}\left|I_{i, j}^{C}\right|,
$$

The source term for water on the cathode side includes electrochemical reaction and transfer from anode side

$$
r_{C, i, j}^{\mathrm{H}_{2} \mathrm{O}}=S_{i, j} \frac{\nu^{\mathrm{H}_{2} \mathrm{O}}}{n_{e}^{C} F}\left|I_{i, j}^{C}\right|+S_{i, j} n_{d, i, j} \frac{\left|I_{i, j}^{\mathrm{C}}\right|}{F},
$$

An empirical equation for calculating electro-osmotic drag coefficient $n_{d}$ is taken from Ren et al. [13]. For the inert nitrogen component, the corresponding source term is equal to zero $\left(r_{C, i, j}^{\mathrm{N}_{2}}=0\right)$.

2.2.2. Electrolyte Current. For fuel cells operating under potentiostatic mode $\left(E_{\text {cell }}=\right.$ const), the current density in PEM electrolyte media is estimated from the voltage equation:

$$
I_{i, j}^{\text {cell }}=\frac{\left(E_{i, j}^{\mathrm{OCV}}-E_{\mathrm{cell}}-\eta_{\mathrm{act}, i, j}^{\mathrm{A}}+\eta_{\mathrm{act}, i, j}^{\mathrm{C}}\right)}{R_{i, j}^{\mathrm{Ohmic}}},
$$

where $\eta_{\mathrm{act}, i, j}^{A}$ is the anode activation overpotential, $\eta_{\mathrm{act}, i, j}^{A}=$ $\eta_{i, j}^{A}-\eta_{\mathrm{eq}}^{A} ; \eta_{\mathrm{act}, i, j}^{C}$ is the cathode activation overpotential, 
$\eta_{\text {act }, i, j}^{C}=\eta_{i, j}^{C}-\eta_{\text {eq }}^{C} ; \eta_{\text {eq }}^{A}, \eta_{\mathrm{eq}}^{C}$ is the anodic and cathodic equilibrium potential differences; $\eta_{i, j}^{A}, \eta_{i, j}^{C}$ is the anode and cathode potential differences at the electrode/membrane interfaces; $R_{i, j}^{\text {Ohmic }}$ is the ohmic resistance.

As shown in Appendix B, voltage (22) is applicable for calculating the current in PEM under a linear membrane phase potential profile. Membrane conductivity is given by the following empirical relation [14]:

$$
\sigma_{m}=\left(0.0005139 C_{m}-0.000326\right) \exp \left(1268\left(\frac{1}{303}-\frac{1}{T}\right)\right) .
$$

2.3. Heat Transfer Submodel. The source terms in energy balance equations for anode (6) and cathode channels (7) are defined as follows:

$$
\begin{aligned}
& q_{i, j}^{A}=\alpha^{A} S_{i, j}\left(T_{i, j}^{S}-T_{i, j}^{A}\right), \\
& q_{i, j}^{C}=\alpha^{C} S_{i, j}\left(T_{i, j}^{S}-T_{i, j}^{C}\right) .
\end{aligned}
$$

The source term in energy balance equation (8) for MEA is

$$
\begin{aligned}
q_{i, j}^{S}= & \delta_{m} S_{i, j} R_{i, j}^{\mathrm{Ohmic}}\left(I_{i, j}^{\text {cell }}\right)^{2}-\Delta H_{R} N_{C, i, j}^{\mathrm{H}_{2} \mathrm{O}}+S_{i, j} E_{\text {cell }}{ }_{i, j}^{\text {cell }} \\
& +\left(S_{i, j} \alpha^{C}+\sum_{k} C_{p}^{(k)} N_{C, i, j}^{(k)}\right)\left(T_{i, j}^{C}-T_{i, j}^{S}\right) \\
& +\left(S_{i, j} \alpha^{A}+\sum_{k} C_{p}^{(k)} N_{A, i, j}^{(k)}\right)\left(T_{i, j}^{A}-T_{i, j}^{S}\right)
\end{aligned}
$$

Additional source terms in energy equations (6) and (7) take into account heat transfer from channels to the anode and cathode collectors

$$
\begin{aligned}
& q_{\text {coll }, i, j}^{A}=\alpha_{\text {coll }}^{A} S_{i, j}\left(T_{\text {coll }}-T_{i, j}^{A}\right), \\
& q_{\text {coll }, i, j}^{C}=\alpha_{\text {coll }}^{C} S_{i, j}\left(T_{\text {coll }}-T_{i, j}^{C}\right) .
\end{aligned}
$$

Convective heat transfer coefficients $\alpha^{C}$ and $\alpha^{A}$ are calculated from empirical correlations for laminar heat transfer in channels. Heat transfer coefficients $\alpha_{\text {coll }}$ are found by a technique proposed by Siegel et al. [15].

2.4. Mass Transfer Submodel. Component molar fluxes for species on the cathode side are defined by mass transfer in gas phase:

$$
N_{i, j}^{(k)}=S_{i, j} \rho_{\mathrm{mol}, G} \beta_{G, \mathrm{eff}}^{(k)}\left(y_{i, j}^{(k)}-y_{\mathrm{cat}, i, j}^{(k)}\right), \quad k=\mathrm{O}_{2}, \mathrm{H}_{2} \mathrm{O},
$$

where $\beta_{G \text {,eff }}^{(k)}$ is the effective mass transfer coefficient in gas phase for $k$ component; $y_{i, j}^{(k)}, y_{\text {cat }, i, j}^{(k)}$ are mole fraction of $k$ component in $(i, j)$ tank in channel and catalyst surface, respectively.

The multicomponent mixture in gas phase includes carbon dioxide, methanol and water in equilibrium with the liquid phase. Component molar fluxes for species on the anode side are defined by mass transfer in liquid phase:

$$
\begin{array}{r}
N_{i, j}^{(k)}=S_{i, j} \rho_{\mathrm{mol}, L} \beta_{L, \mathrm{eff}}^{(k)}\left(x_{i, j}^{(k)}-x_{\mathrm{cat}, i, j}^{(k)}\right), \\
k=\mathrm{MeOH}, \mathrm{CO}_{2}, \mathrm{H}_{2} \mathrm{O} .
\end{array}
$$

2.5. Gas Evolution. Gas evolution results from interphase mass transfer of carbon dioxide in the anode channels. The source term in balance equation for gas phase (2) describes the rate of desorption and absorption processes in the anode channels. The conventional submodel for estimating the source term is based on mass transfer equation

$$
r_{\text {desorp }, i, j}=S_{i, j} k_{V} \rho_{\mathrm{mol}, G}\left(y_{i, j}^{\mathrm{CO}_{2}}-y_{\mathrm{sat}, i, j}^{\mathrm{CO}_{2}}\right),
$$

where $k_{V}$ is an empirical volumetric mass transfer coefficient.

It is generally assumed that the multicomponent gas phase is in equilibrium with the liquid phase. Using the equilibrium condition, Danilov et al. [4-6] proposed the following equation for estimating the source term in anode channels:

$$
r_{\text {desorp }, i, j}=\gamma\left(\psi+r_{A, i, j}^{\mathrm{CO}_{2}}\right),
$$

where $\gamma$ is the splitting factor; $\psi$ is the coefficient. The derivation of the auxiliary equation for coefficient $\psi$ is given in [4-6]. The local splitting factor $\gamma$ is found from solving the equilibrium flash equation [4-6]. It should be noted that new submodel (32) corresponds to an equilibrium model of multicomponent mass transfer between liquid and gas in the anode channels [4-6].

According to the physical meaning of the mass balance equations, molar component concentration is defined as mixture concentrations for gas-liquid flow in channels. Component mole fraction in liquid phase $\left(x^{(k)}\right)$ can be expressed through mixture concentration $\left(C^{(k)}\right)$ with known gas volume fraction $\left(\varphi_{G}\right)$. As shown in Appendix $C$, the condition of thermodynamic equilibrium in the multicomponent gas-liquid mixture gives the next relationship for the specie mole fraction in liquid phase

$$
x^{(k)}=\frac{C^{(k)}}{K^{(k)} \varphi_{G} \rho_{\mathrm{mol}, G}+\left(1-\varphi_{G}\right) \rho_{\mathrm{mol}, L}},
$$

where $K^{(k)}$ is the distribution coefficient for $k$-component, $K^{(k)}=y^{(k)} / x^{(k)}$.

\section{Results and Discussion}

Modeling and simulations are valuable tools for improving our understanding of the heat and mass transfer processes in fuel cells. To validate the improved TSR model, we used experimental data reported by Murgia et al. [2] for a $25 \mathrm{~cm}^{2}$ DMFC operating with $1.5 \mathrm{M}$ and $1 \mathrm{M}$ aqueous methanol feeds at $90^{\circ} \mathrm{C}$. Operating conditions for this DMFC are listed in Table 1.

The number of tanks is set as $n_{i}=4$ and $n_{j}=4$, corresponding to a TSR model with 272 nonlinear coupled 
TABLE 1: Operating conditions for the DMFC.

\begin{tabular}{lc}
\hline Parameter & \\
\hline Fuel flow rate, $\mathrm{cm}^{3} / \mathrm{min}$ & 15 \\
Oxidant flow rate, $\mathrm{cm}^{3} / \mathrm{min}$ & 1000 \\
$\mathrm{MeOH} \mathrm{M}$ in fuel & $1.5 \mathrm{M} ; 1 \mathrm{M}$ \\
$\mathrm{CO}_{2}, \mathrm{~m}$.fr. in fuel & $1.0 \times 10^{-4}$ \\
$\mathrm{O}_{2}$ mol fraction in oxidant & 0.99 \\
Temperature, C & 90 \\
Pressure, atm & 1
\end{tabular}

TABLE 2: Geometry and electrochemical parameters for DMFC.

\begin{tabular}{lcc}
\hline Parameter & Anode & Cathode \\
\hline Exchange current density $I_{0}, \mathrm{~A} \mathrm{~m}^{-2}$ & 47.1 & 0.042 \\
Reference concentration $C_{\text {ref }}, \mathrm{M}$ & 2 & 0.034 \\
Charge transfer coefficient $\alpha_{A}$ & 0.5 & 0.8 \\
Charge transfer coefficient $\alpha_{C}$ & 0.5 & 1.2 \\
Channel height, $\mathrm{m}$ & \multicolumn{2}{c}{$1 \times 10^{-3}$} \\
Electrode area $S, \mathrm{~m}^{2}$ & \multicolumn{2}{c}{$25 \times 10^{-4}$} \\
Membrane width $\delta_{m}, \mathrm{~m}$ & \multicolumn{2}{c}{$2 \times 10^{-4}$} \\
Catalyst width $\delta_{\text {cat }}, \mathrm{m}$ & \multicolumn{2}{c}{$1 \times 10^{-5}$} \\
\hline
\end{tabular}

first-order ordinary differential equations. The accepted number of tanks corresponds to the laminar flow regime in the channels with parallel flow field design. The developed TSR model was implemented in MATLAB, and it was initialized with the feed composition and temperature. The geometry and electrochemical parameters of DMFC are listed in Table 2.

Figure 2 compares the experimental and calculated polarization curves for DMFC with operating conditions in Table 1. The solid line represents a DMFC model prediction with the improved TSR model.

Figure 3 displays histograms with steady-state simulation results predicted by the TSR model for DMFC with $1.0 \mathrm{M}$ feed of fuel at the anode and pure oxygen feed at the cathode. It should be noted that each tank is characterized by complete mixing, and distribution of concentration, temperature, and current density is presented by step change for tanks in series. Concentration of methanol in channel is decreased due to the anode electrochemical reaction. For the anode channels, carbon dioxide is the product of the anode electrochemical reaction. Gas content in the anode channels is increased from inlet to the outlet following the trend in molar $\mathrm{CO}_{2}$ concentration. The two-dimensional histograms indicate a strong coupling between the reactants and the current density distribution. The predicted current density profile is following the trend in methanol concentration in anode channels. Murgia et al. [2] obtained experimental polarization data by circulating aqueous methanol from a reservoir where $\mathrm{CO}_{2}$ was released to the atmosphere. The inlet $\mathrm{CO}_{2}$ concentration in the liquid fuel in Table 1 corresponds to the gas-liquid equilibrium condition in the fuel reservoir. The predicted temperature profile in MEA is following the main trend in the current density distribution.

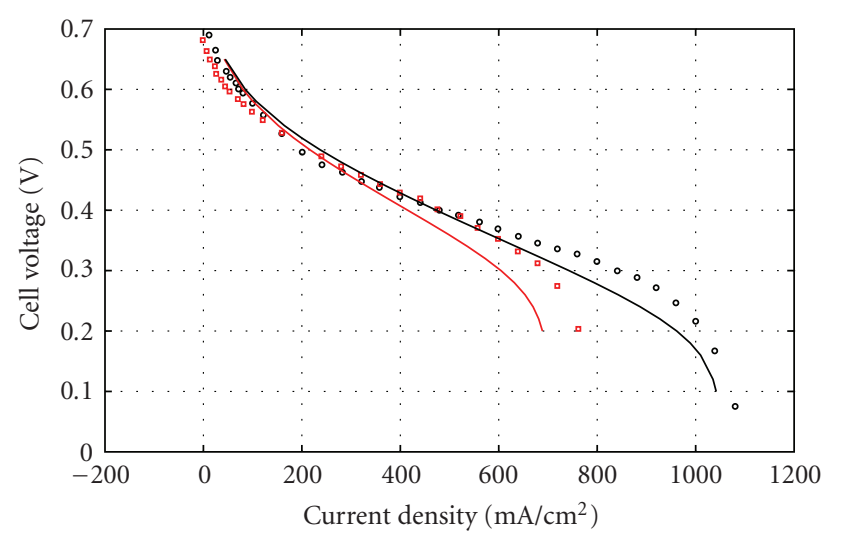

$$
\begin{array}{ll}
-1 \mathrm{M} & - \text { TSR model } \\
-1.5 \mathrm{M} & - \text { TSR model }
\end{array}
$$

FIGURE 2: Comparison of the polarization curves predicted by TSR model with experimental data [2].

Figure 4 presents histograms with steady-state simulation results predicted by the TSR model for DMFC with $1.5 \mathrm{M}$ feed of fuel at the anode and pure oxygen feed at the cathode.

Gas management greatly influences the performance of the fuel cell. On the anode side, carbon dioxide is produced by electrochemical oxidation of the methanol. Inefficient removal of $\mathrm{CO}_{2}$ bubbles may block anode channels and decrease efficiency of the fuel cells due to limited mass transport and maldistribution of reactants. According to the conventional submodel, the interface flux is completely dependent on empirical mass transfer coefficient $\left(k_{V}\right)$. The predicted gas content in the anode channels can vary from 0 to $90 \%$ depending on the value of the mass transfer coefficient. Simulation results reveal that high values of the mass transfer coefficient $\left(k_{V}>6000 \mathrm{~s}^{-1}\right)$ predict gas evolution in the anode channels with high gas content $(\varphi>$ $40 \%)$. For low mass transfer coefficients $\left(k_{V}<6000 \mathrm{~s}^{-1}\right)$, on the other hand, $\varphi<40 \%$. The volumetric mass transfer coefficient $k_{V}=6000 \mathrm{~s}^{-1}$ used in gas evolution submodel (31) provides the condition $\varphi \approx 40 \%$ in the anode channels, which is close to the equilibrium condition given by the flash equation.

As shown in Figure 5, empirical model (31) and new submodel (32) for gas evolution predict similar trends in the gas content distribution. In contrast to nonequilibrium submodel (31) with empirical mass transfer, new rate expression (32) determines the gas content under equilibrium conditions without empirical coefficients.

Comparison of DMFC performance with different fuel composition is given in Table 3. Changing the fuel composition from $1 \mathrm{M}$ to $1.5 \mathrm{M}$ gives a small improvement in fuel cell performance. The mass transfer coefficient is presented in the form of limiting current density. Average current density approaches the value of limiting current densities under cell voltage $E_{\text {cell }}=0.2 \mathrm{~V}$. The possible way of DMFC performance improvement is to intensify mass transfer from the channels to the catalyst layer. 


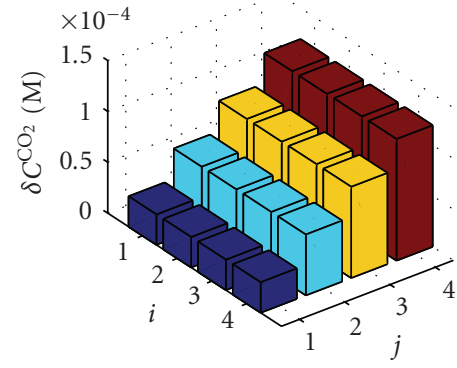

(a)

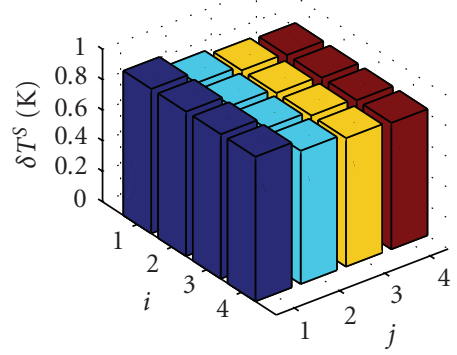

(d)

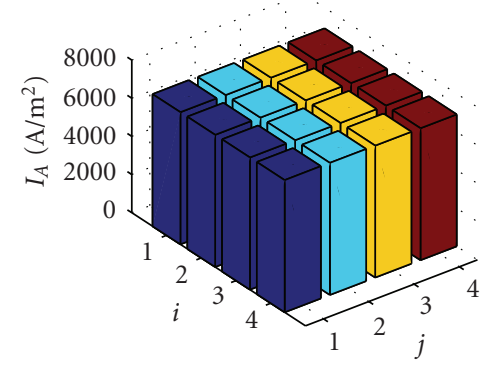

(b)

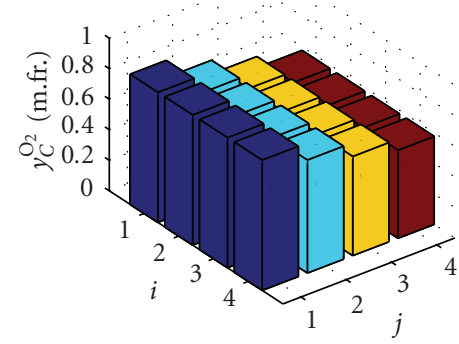

(e)

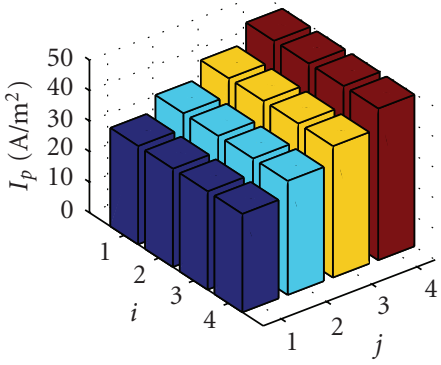

(c)

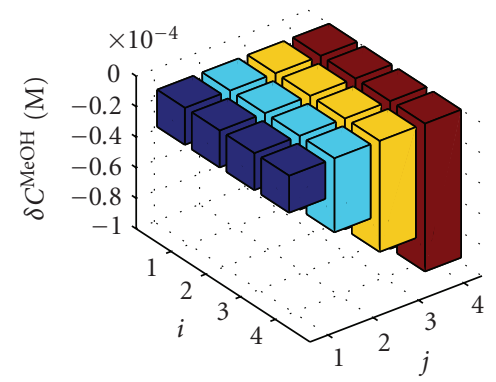

(f)

FIGURE 3: Histograms with steady-state simulation results predicted by TSR model for DMFC with coflow mode of fuel and oxidant $\left(E_{\text {cell }}=\right.$ $0.2 \mathrm{~V}$ ). Numerical modelling of fuel cell with anode $1.0 \mathrm{M}$ feed of fuel and pure oxygen feed at the cathode. Temperature variation $\delta T_{i, j}^{S}=$ $T_{i, j}^{S}-T_{\mathrm{in}}^{\mathrm{C}}$. Methanol molar concentration variation $\delta C_{i, j}^{\mathrm{MeOH}}=C_{i, j}^{\mathrm{MeOH}}-C_{\mathrm{in}}^{\mathrm{MeOH}}$. Carbon dioxide molar concentration variation $\delta C_{i, j}^{\mathrm{CO}_{2}}=$ $C_{i, j}^{\mathrm{CO}_{2}}-C_{\mathrm{in}}^{\mathrm{CO}_{2}}$.

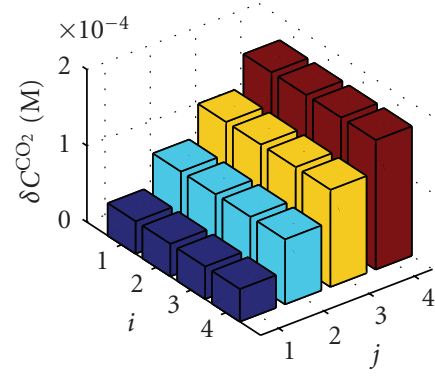

(a)

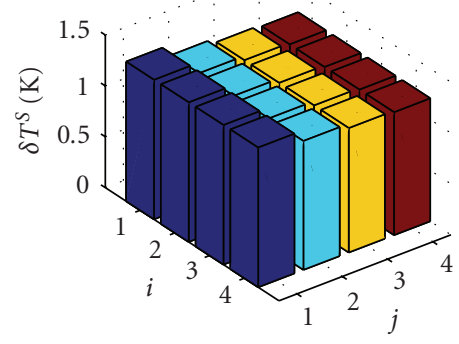

(d)

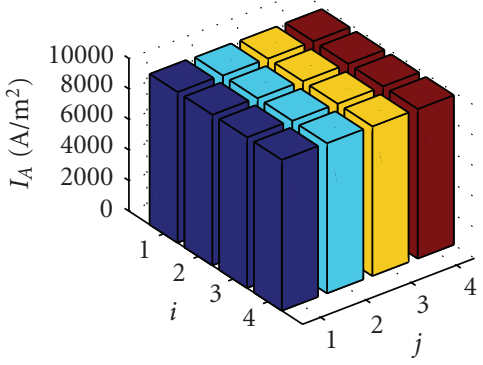

(b)

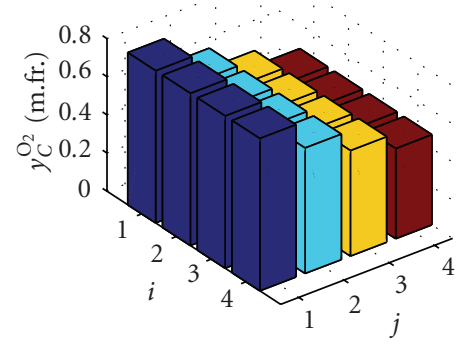

(e)

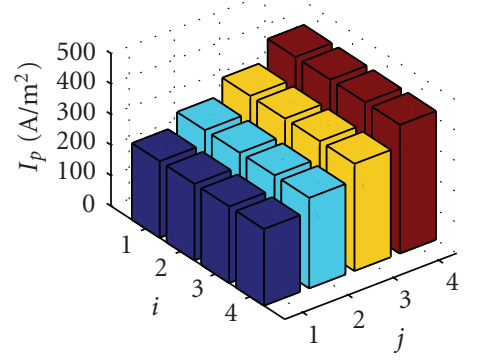

(c)

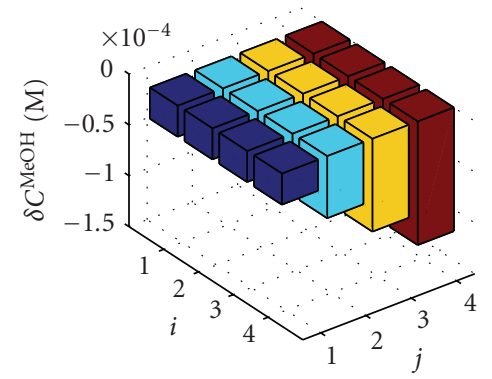

(f)

FIGURE 4: Histograms with steady-state simulation results predicted by TSR model for DMFC with coflow mode of fuel and oxidant $\left(E_{\text {cell }}=\right.$ $0.2 \mathrm{~V})$. Numerical modelling of fuel cell with anode $1.5 \mathrm{M}$ feed of fuel and pure oxygen feed at the cathode. Temperature variation $\delta T_{i, j}^{S}=$ $T_{i, j}^{S}-T_{\mathrm{in}}^{C}$. Methanol molar concentration variation $\delta C_{i, j}^{\mathrm{MeOH}}=C_{i, j}^{\mathrm{MeOH}}-C_{\mathrm{in}}^{\mathrm{MeOH}}$. Carbon dioxide molar concentration variation $\delta C_{i, j}^{\mathrm{CO} 2}=$ $C_{i, j}^{\mathrm{CO}_{2}}-C_{\mathrm{in}}^{\mathrm{CO}_{2}}$. 


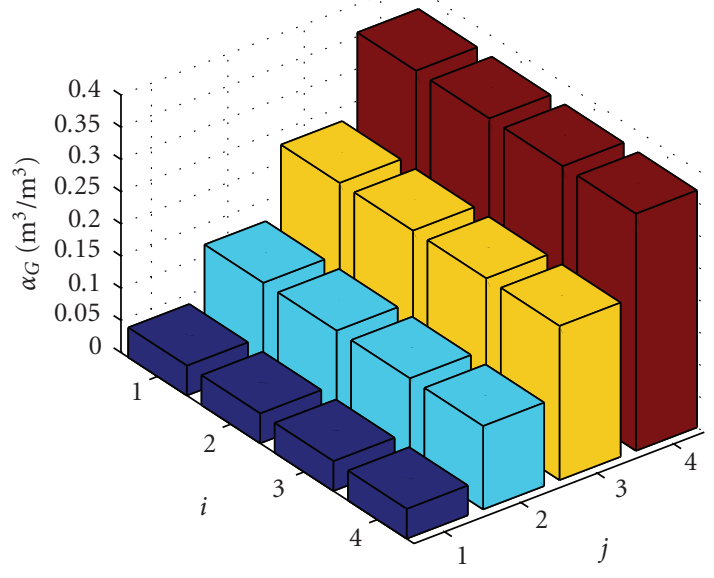

(a)

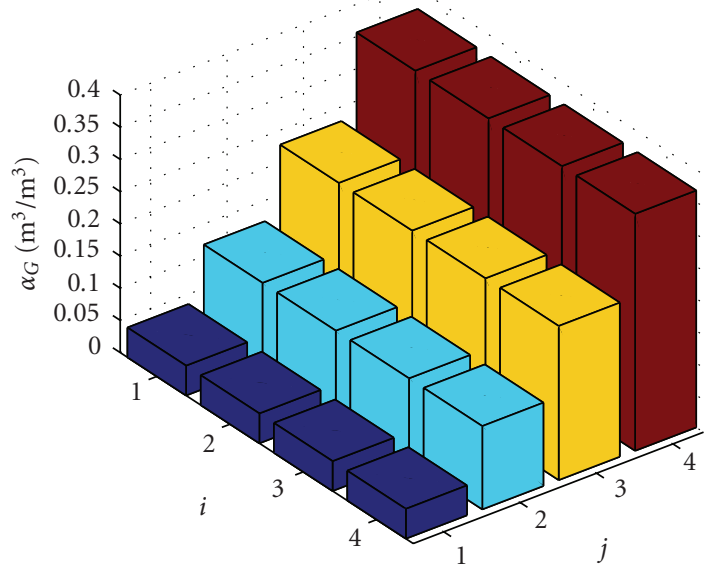

(b)

FIGURE 5: Histograms with gas content in anode channels predicted by TSR model for DMFC with (a) empirical mass transfer (31) and (b) new gas evolution submodel $(32)\left(E_{\text {cell }}=0.2 \mathrm{~V}\right)$.

TABLE 3: Single DMFC cell simulation results $\left(E_{\text {cell }}=0.2 \mathrm{~V}\right)$.

\begin{tabular}{|c|c|c|c|c|c|c|}
\hline Parameter & $\begin{array}{c}\text { Outlet gas } \\
\text { content } \\
\varphi_{\text {out }}^{A} \\
\mathrm{~m}^{3} / \mathrm{m}^{3}\end{array}$ & $\begin{array}{c}\text { Mean parasitic } \\
\text { current } \\
\bar{I}_{\text {par }} \\
\mathrm{A} / \mathrm{m}^{2}\end{array}$ & $\begin{array}{c}\text { Mean limiting } \\
\text { current } \\
\bar{I}_{\lim }^{A} \\
\mathrm{~A} / \mathrm{m}^{2}\end{array}$ & $\begin{array}{c}\text { Mean anode } \\
\text { current } \\
\bar{I}^{A} \\
\mathrm{~A} / \mathrm{m}^{2}\end{array}$ & $\begin{array}{c}\text { Fuel } \\
\text { utilization } \\
\text { FU } \\
\%\end{array}$ & $\begin{array}{c}\text { Oxidant } \\
\text { utilization } \\
\text { AU } \\
\%\end{array}$ \\
\hline $1.0 \mathrm{M}$ & 0.27 & 39.1 & 7009 & 6905.2 & 0.01 & 8.1 \\
\hline $1.5 \mathrm{M}$ & 0.36 & 329.8 & 10514 & 9819.9 & 0.01 & 11.8 \\
\hline
\end{tabular}

\section{Conclusions}

This study presents a TSR model for DMFC operating in potentiostatic mode. The developed TSR model includes mass and energy balance equations in anode and cathode compartments together with gas evolution in anode channels. Modified charge balance equations are defined as interface boundary conditions. The possibility of evaluating two-dimensional profiles in the DMFC is one of the main advantages of the developed TSR model. The simulation results indicate the strong coupling between concentration, temperature and current density distribution in coflow DMFC. Taking into account the assumption of uniform distribution of fuel and oxidant in channels, the TSR model predicts the limiting performance of the DMFC under the given flow regime (number of tanks), mass transfer and catalyst activity. The improved TSR model allows studying the influence of different parameters on the DMFC performance. Results can be used to better understand and investigate the effects of various parameters and operating conditions on DMFC performance.

\section{Appendices}

\section{A. Derivation of Charge Balance Equation}

The electric potential fields are governed by the charge conservation equations. The charge balance at the interface between electron-conducting and ion-conducting media is given by [16]

$$
\frac{\partial Q}{\partial t}+\nabla \cdot i_{\mathrm{s}}=\left(I_{1}-I_{2}\right)
$$

where $I_{1}$ is the current in electron-conducting media normal to the boundary, $I_{2}$ is the current in ion-conducting media normal to the boundary, $i_{s}$ is the superficial current density, $Q$ is the charge. For the TSR model, the net charge flux is zero $\left(\nabla \cdot i_{s}=0\right)$. The interfaces between ionic and electronic media behave like a capacitor in which the charge density is a function of potential difference across the double layer. Charge or discharge rate at the electrode-electrolyte double layer can be represented as

$$
\frac{\partial Q}{\partial t}=C_{\mathrm{dl}} \frac{\partial \eta}{\partial t}
$$

For the difference of potential of the electron conducting media $\phi$ and the potential of the electrolyte phase $\phi_{m}$, the following charge conservation equation is valid:

$$
\frac{\partial \eta}{\partial t}=\frac{1}{C_{\mathrm{dl}}}\left(I_{1}-I_{2}\right)
$$

where $\eta$ is potential differences or overpotential, $\eta=\phi-\phi_{m}$.

The improved fuel cell models with new charge balance equation provide a better understanding of main phenomena governing electrochemical reactions in fuel cells $[4-6,11$, 12]. 


\section{B. Electrolyte Current}

By definition, the electrolyte current is written as follows:

$$
I_{m}=-\sigma_{m} \frac{\partial \phi_{m}}{\partial n}
$$

Here $\phi_{m}$ represents the potential in the ionic conducting media; $n$ is the normal to the interface; $\sigma_{m}$ is the membrane conductivity. Using linear approximation of the potential profile in the ionic conducting media, the electrolyte current is defined as follows:

$$
I_{m} \approx-\sigma_{m}\left(\frac{\phi_{m}^{C}-\phi_{m}^{A}}{\delta_{m}}\right),
$$

where $\delta_{m}$ is the membrane thickness; $\phi_{m}^{C}$ is the membrane phase potential at cathode electrode/membrane interface; $\phi_{m}^{A}$ is the membrane phase potential at anode electrode/membrane interface. The values of potential in ionic conducting media at electrode/membrane interfaces can be expressed through potential difference $\eta$ given by the definition of the activation overpotential

$$
\begin{aligned}
& \eta_{\mathrm{act}}^{A}=\phi^{A}-\phi_{m}^{A}-\eta_{\mathrm{eq}}^{A}, \\
& \eta_{\mathrm{act}}^{C}=\phi^{C}-\phi_{m}^{C}-\eta_{\mathrm{eq}}^{C},
\end{aligned}
$$

where $\phi^{C}$ is the potential at cathode electrode/membrane interface in the electron conducting media; $\phi^{A}$ is the potential at anode electrode/membrane interface in the electron conducting media.

We note that the reversible Nernst potential at the electrode/membrane interface is linked with anodic and cathodic equilibrium potential differences:

$$
\eta_{\mathrm{eq}}^{C}-\eta_{\mathrm{eq}}^{A}=E^{\mathrm{OCV}}
$$

It is known that the difference of the anodic and cathodic electric potential is equal to the cell voltage

$$
E_{\text {Cell }}=\phi^{C}-\phi^{A}
$$

The values of potential in ionic conducting media at electrode/electrolyte interfaces can be expressed from (B.3) as follows:

$$
\begin{gathered}
\phi_{m}^{A}=\phi^{A}-\eta_{\mathrm{act}}^{A}-\eta_{\mathrm{eq}}^{A}, \\
\phi_{m}^{C}=\phi^{C}-\eta_{\mathrm{act}}^{C}-\eta_{\mathrm{eq}}^{C} .
\end{gathered}
$$

Taking into account equations (B.2)-(B.6), we obtain the next expression for the electrolyte current density:

$$
I_{m}=\frac{\left(E^{\mathrm{OCV}}-E_{\mathrm{cell}}-\eta_{\mathrm{act}}^{A}+\eta_{\mathrm{act}}^{C}\right)}{R^{\mathrm{Ohmic}}},
$$

where $R^{\text {Ohmic }}$ is the ohmic resistance, $R^{\text {Ohmic }}=\delta_{m} / \sigma_{m}$.

Application of new expression for electrolyte current with fuel cell models is shown in our papers $[4-6,11,12]$.

\section{Definition of Mixture Concentration}

Mass balance equations for channels and catalyst layer are defined with molar component concentration. In view of gas-liquid flow in channels, the physical meaning of component concentration corresponds to mixture concentration. By definition, the mixture concentration is

$$
C^{*}=C_{G}^{*} \varphi_{G}+C_{L}^{*}\left(1-\varphi_{G}\right)
$$

where $C^{*}$ is mixture concentration, $\mathrm{kg} / \mathrm{m}^{3} ; C_{G}^{*}$ is concentration in gas phase, $\mathrm{kg} / \mathrm{m}^{3} ; C_{L}^{*}$ is concentration in liquid phase, $\mathrm{kg} / \mathrm{m}^{3}$. Dividing both parts by molecular weight, we transfer to molar mixture concentration

$$
\frac{C^{*}}{M}=\frac{C_{G}^{*} \varphi_{G}}{M}+\frac{C_{L}^{*}\left(1-\varphi_{G}\right)}{M}
$$

or

$$
C^{(k)}=y^{(k)} \varphi_{G} \rho_{\mathrm{mol}, G}+x^{(k)}\left(1-\varphi_{G}\right) \rho_{\mathrm{mol}, L}
$$

where $C$ is mixture concentration, $\mathrm{mol} / \mathrm{m}^{3} ; C_{G}$ is concentration in gas phase, $\mathrm{mol} / \mathrm{m}^{3} ; C_{L}$ is concentration in liquid phase, $\mathrm{mol} / \mathrm{m}^{3}$. The condition of thermodynamic equilibrium in multicomponent gas-liquid mixture gives the relationship among species concentrations in phases

$$
x^{(k)}=\frac{C^{(k)}}{K^{(k)}\left(1-\varphi_{G}\right) \rho_{\mathrm{mol}, G}+\left(1-\varphi_{G}\right) \rho_{\mathrm{mol}, L}} .
$$

Equation (C.4) is used for calculating the driving mass transfer force in mass transfer equation.

\section{Abbreviations}

\section{Latin Letters}

C: $\quad$ Molar concentration $/ \mathrm{mol} \mathrm{m}^{-3}$

$C_{\mathrm{dL}}: \quad$ Double layer capacitance

$C_{p}: \quad$ Specific heat $/ \mathrm{J} \mathrm{mol}^{-1} \mathrm{~K}^{-1}$

$C_{m}: \quad$ Water content in membrane $/ \mathrm{mol} \mathrm{m}^{-3}$

$E_{\text {cell }}:$ Cell voltage/V

$E^{\text {ocv }}$ Open circuit voltage/V

$F^{A}, F^{C}$ : Anode and cathode volumetric flow rate $/ \mathrm{m}^{3} \mathrm{~s}^{-1}$

F: $\quad$ Faraday's constant/96485 $\mathrm{C} \mathrm{mol}^{-1}$

$K$ : $\quad$ Distribution coefficient

$k_{V}$ : Volumetric mass transfer coefficient $/ \mathrm{s}^{-1}$

$h: \quad$ Enthalpy/J mole ${ }^{-1}$

$\Delta H_{R}:$ Reaction enthalpy/ $\mathrm{J} \mathrm{mol}^{-1}$

I: $\quad$ Current density/A $\mathrm{m}^{-2}$

$I_{0}$ : $\quad$ Exchange current density/A m $\mathrm{m}^{-2}$

MEA: Membrane electrode assembly

$N$ : $\quad$ Component molar flux $/ \mathrm{mol} \mathrm{s}^{-1}$

$n$ : $\quad$ Number of tanks

$n_{d}: \quad$ Net drug coefficient

$n_{e}: \quad$ Number of electrons

$P: \quad$ Pressure/Pa 


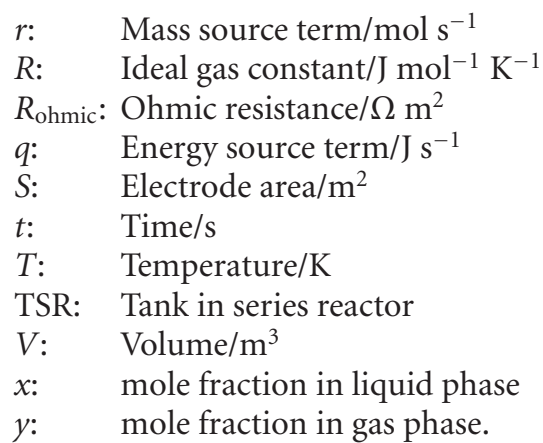

Greek Symbols

$\alpha$ : Heat transfer coefficient $/ \mathrm{W} \mathrm{m}^{-2} \mathrm{~K}^{-1}$

$\alpha_{A}^{A}$ : Anodic charge transfer coefficients for anode

$\alpha_{C}^{A}$ : Cathodic charge transfer coefficients for anode

$\alpha_{A}^{C}$ : Anodic charge transfer coefficients for cathode

$\alpha_{C}^{C}$ : Cathodic charge transfer coefficients for cathode

$\beta_{\text {eff: }}$ Effective mass transfer coefficient $/ \mathrm{m} \mathrm{s}^{-1}$

$\nu$ : Stoichiometry coefficient

$\eta$ : $\quad$ Potential difference/V

$\rho_{\text {mol }}$ : Molar density $/ \mathrm{mol} \mathrm{m}^{-3}$

$\sigma: \quad$ Conductivity $/ \Omega^{-1} \mathrm{~m}^{-1}$

$\delta_{m}:$ Membrane thickness $/ \mathrm{m}$

$\delta_{\text {cat }}:$ Catalyst thickness $/ \mathrm{m}$

$\varphi_{G}:$ Gas content $/ \mathrm{m}^{3} \mathrm{~m}^{-3}$.

\section{Subscripts/Superscripts}

$\begin{array}{ll}\text { in: } & \text { Inlet } \\ \text { out: } & \text { Outlet } \\ \text { eff: } & \text { Effective } \\ \text { i,j: } & i, j \text { tank } \\ \text { A: } & \text { Anode } \\ \text { C: } & \text { Cathode } \\ \text { cell: } & \text { Fuel cell } \\ \text { G: } & \text { Gas phase } \\ \text { lim: } & \text { Limiting } \\ \text { mol: } & \text { Molar } \\ \text { m: } & \text { Membrane } \\ \text { par: } & \text { Parasitic } \\ \text { ref: } & \text { Reference } \\ \text { S: } & \text { Interface; solid } \\ \text { sat: } & \text { Saturated } \\ \mathrm{MeOH} \text { Methanol } \\ \mathrm{O}_{2}: & \text { Oxygen } \\ \mathrm{H}_{2} \mathrm{O}: & \text { Water } \\ \mathrm{N}_{2}: & \text { Nitrogen } \\ \mathrm{CO}_{2}: & \text { Carbon dioxide. }\end{array}$

\section{Acknowledgment}

The authors are grateful to IWT Vlaanderen, for financial support for OCPEC "Optimised Chemical Production with Electricity Cogeneration".

\section{References}

[1] A. A. Kulikovsky, "1D + 1D model of a DMFC: localized solutions and mixedpotential," Electrochemistry Communications, vol. 6, no. 12, pp. 1259-1265, 2004.

[2] G. Murgia, L. Pisani, A. K. Shukla, and K. Scott, "A numerical model of a liquid-feed solid polymer electrolyte DMFC and its experimental validation," Journal of the Electrochemical Society, vol. 150, no. 9, pp. A1231-A1245, 2003.

[3] M. S. Hyun, S. K. Kim, D. Jung et al., "Prediction of anode performances of direct methanol fuel cells with different flowfield design using computational simulation," Journal of Power Sources, vol. 157, no. 2, pp. 875-885, 2006.

[4] V. A. Danilov, J. Lim, I. L. Moon, and K. H. Choi, "Gas management in flow field design using 3D direct methanol fuel cell model under high stoichiometric feed," Korean Journal of Chemical Engineering, vol. 23, no. 5, pp. 753-760, 2006.

[5] V. A. Danilov, J. Lim, I. L. Moon, and H. Chang, "Threedimensional, two-phase, CFD model for the design of a direct methanol fuel cell," Journal of Power Sources, vol. 162, no. 2, pp. 992-1002, 2006.

[6] H. Kim, V. A. Danilov, J. Lim, and I. Moon, "Development of 3D DMFC model for flow field design," The Korean Journal of Chemical Engineering, vol. 45, pp. 93-102, 2007.

[7] K. Sundmacher, T. Schultz, S. Zhou, K. Scott, M. Ginkel, and E. D. Gilles, "Dynamics of the direct methanol fuel cell (DMFC): experiments and model-based analysis," Chemical Engineering Science, vol. 56, no. 2, pp. 333-341, 2001.

[8] K. Sundmacher, A. Kienle, H. J. Pesch, J. F. Berndt, and G. Huppmann, Eds., Molten Carbonate Fuel Cells Modeling, Analysis, Simulation, and Control, Wiley-VCH, Weinheim, Germany, 2007.

[9] U. Krewer, M. Pfafferodt, A. Kamat, D. F. Menendez, and K. Sundmacher, "Hydrodynamic characterisation and modelling of anode flow fields of Direct Methanol Fuel Cells," Chemical Engineering Journal, vol. 126, no. 2-3, pp. 87-102, 2007.

[10] U. Krewer, Y. Song, V. John et al., "Direct methanol fuel cell (DMFC): analysis of residence time behavior of anodic flow bed," Chemical Engineering Science, vol. 59, no. 1, pp. 119-130, 2004.

[11] S. Hosseini, V. A. Danilov, P. Vijay, and M. O. Tadé, "An improved tank in series model for the planar solid oxide fuel cell," Industrial and Engineering Chemistry Research, vol. 50, no. 2, pp. 1056-1069, 2011.

[12] V. A. Danilov, P. Vijay, and M. O. Tade, "An improved TSR model for tubular solid oxide fuel cell stacks," Chemical Engineering \& Technology, vol. 334, no. 5, pp. 737-745, 2011.

[13] X. Ren, T. E. Springer, T. A. Zawodzinski, and S. Gottesfeld, "Methanol transport through nafion membranes electroosmotic drag effects on potential step measurements," Journal of the Electrochemical Society, vol. 147, no. 2, pp. 466-474, 2000.

[14] T. E. Springer, T. A. Zawodzinski, and S. Gottesfeld, "Polymer electrolyte fuel cell model," Journal of the Electrochemical Society, vol. 138, no. 8, pp. 2334-2342, 1991.

[15] N. P. Siegel, M. W. Ellis, D. J. Nelson, and M. R. von Spakovsky, "A two-dimensional computational model of a PEMFC with liquid water transport," Journal of Power Sources, vol. 128, no. 2, pp. 173-184, 2004.

[16] R. Bansal, Handbook of Engineering Electromagnetics, Marcel Dekker, New York, NY, USA, 2004. 


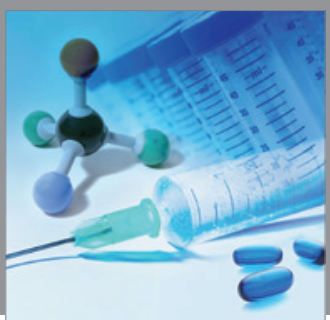

International Journal of

Medicinal Chemistry

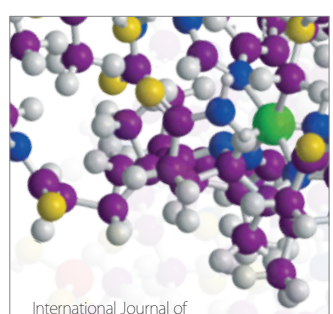

Carbohydrate Chemistry

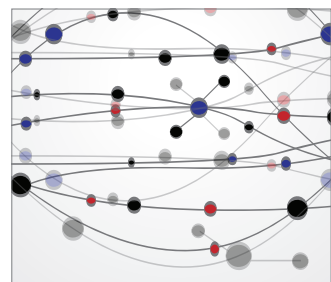

The Scientific World Journal
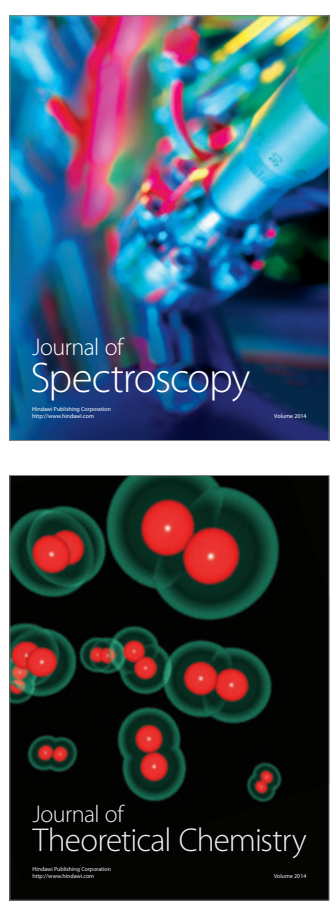
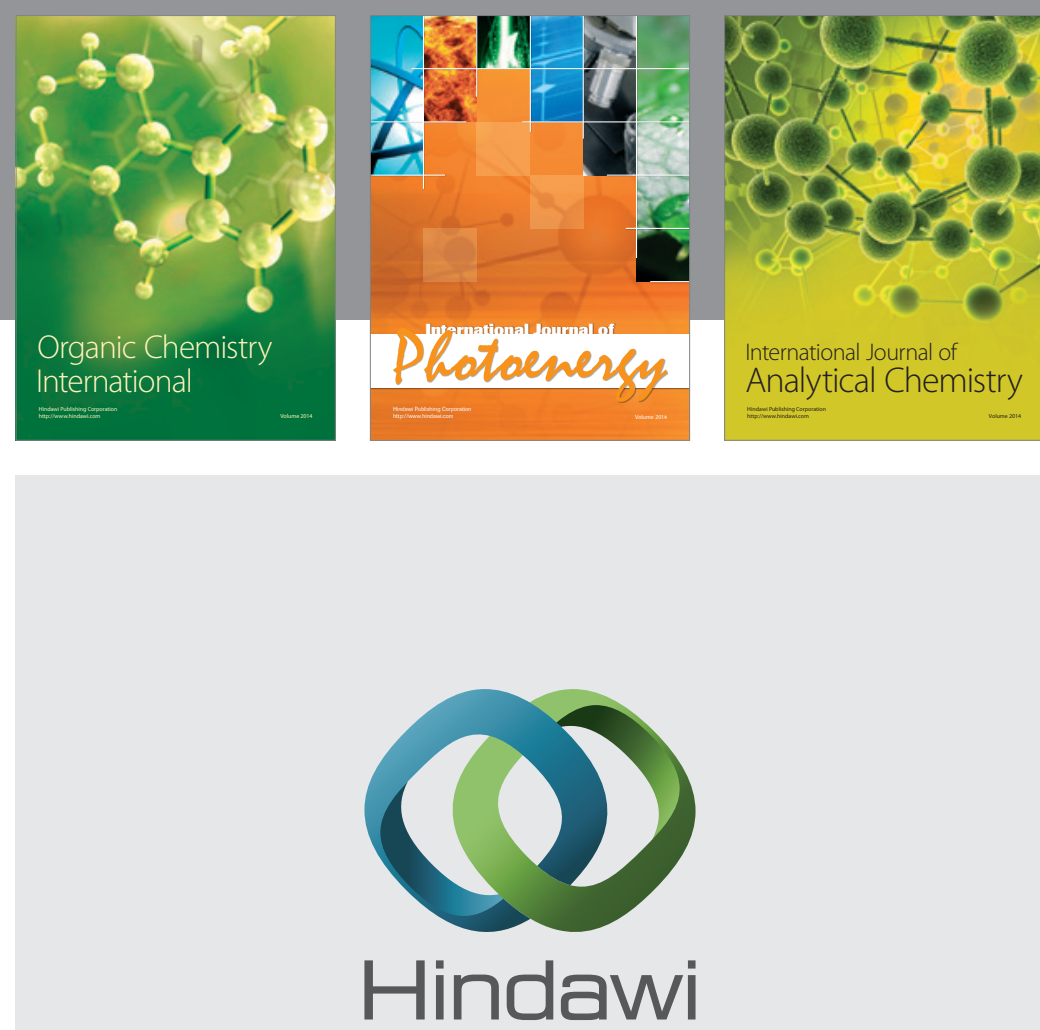

Submit your manuscripts at

http://www.hindawi.com
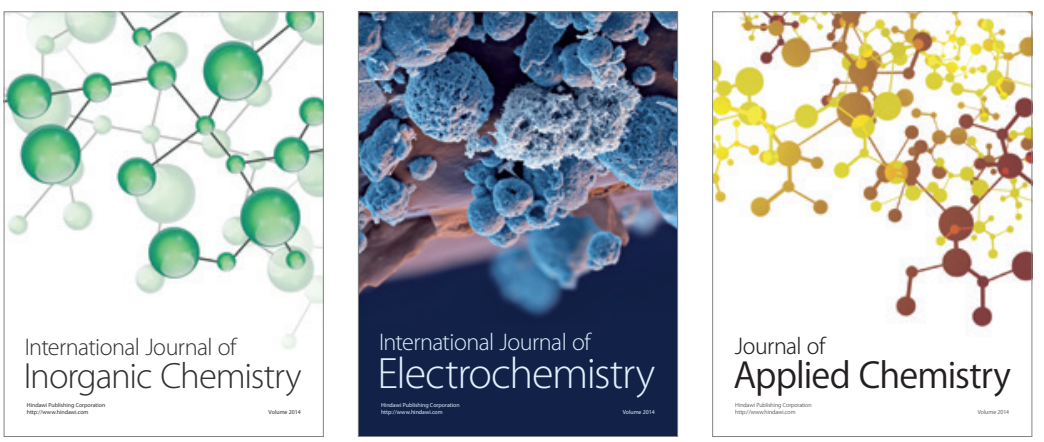

Journal of

Applied Chemistry
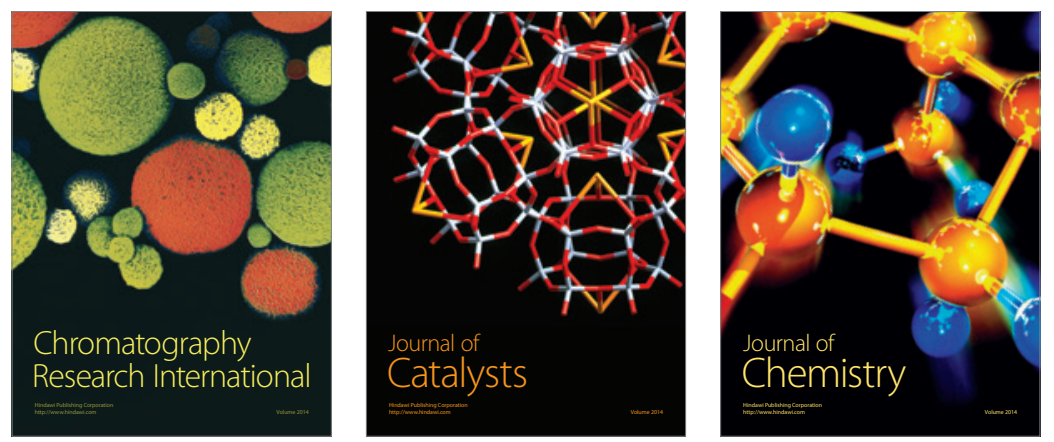
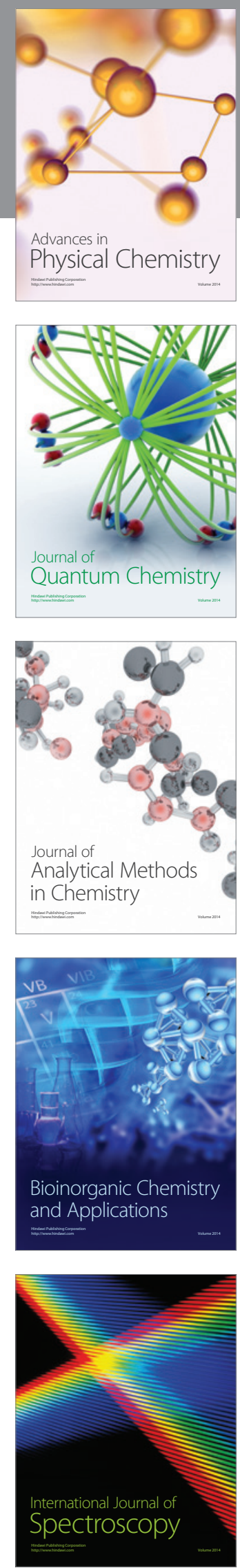